\title{
Concepções de acadêmicos de enfermagem sobre usuários de drogas
}

\author{
Nursing students' conceptions about the user of drugs \\ Concepciones de los estudiantes de enfermería sobre los usuarios de drogas
}

\section{Gertrudes Teixeira Lopes', Bruna Kelly de Jesus Lemos', Helen Balthazar de Lima', Bárbara Rodrigues Carvalho Cordeiro', Luana dos Santos Vasconcellos Lima' \\ 'Universidade do Estado do Rio de Janeiro. Faculdade de Enfermagem. Rio de Janeiro, RJ}

Submissão: 18/08/2008

Aprovação: 20/06/2009

\section{RESUMO}

Objeto do estudo: Concepções dos graduandos de enfermagem sobre a abordagem ao paciente usuário de drogas. Objetivos: Descrever a concepção dos estudantes de enfermagem sobre os usuários de drogas. Método: Estudo descritivo-exploratório desenvolvido com 321 estudantes de 15 Instituições privadas de Ensino Superior de Enfermagem, no estado do Rio de Janeiro. Utilizou-se a escala de atitudes e crenças NEADA, aplicada entre junho de 2006 e agosto de 2007. Os resultados evidenciam Que as dificuldades em abordar um cliente Que faz uso de drogas são reais, mas as limitações pessoais dos profissionais em atender essa clientela ainda permeiam a assistência, influenciando no cuidado.

Descritores: Enfermagem; Estudantes de enfermagem; Drogas ilícitas.

\section{ABSTRACT}

Study's Object: Conceptions of nursing students on the approach to the drugs user. Objectives: To describe the conceptions of nursing students about the user of drugs. Method: Descriptive-exploratory study carried out with 321 students from 15 private nursing schools in the state of Rio de Janeiro. The scale of attitudes and beliefs NEADA was used to obtain the data between June 2006 and August 2007. The results demonstrate that the difficulties in dealing with the client who is a drug user are real, but the personal limitations of professionals in work with this kind of client still permeate the assistance, influencing care.

Descriptors: Nursing; Students, nursing; Street drugs.

\section{RESUMEN}

Objecto del estudio: Concepciones de los estudiantes de enfermería sobre el acercamiento a un paciente usuario de drogas. Objectivos: describir la concepción de los estudiantes de enfermería en los usuarios de drogas. Metodo: estudio descriptivo-exploratorio lo cual se desarrolló con 321 estudiantes de 15 escuelas privadas de grado en enfermería en el estado de Rio de Janeiro. La escala de actitudes y creencia NEADA hay sido utlizada y aplicada el junio del 2006 hasta el Agosto del 2007. Los resultados revelan Que las dificultades en abordar a un cliente Que usa drogas són verdaderos, pero en la asistencia a estos clientes todavía las limitaciones personales de los profesionales impregnan en la asistencia, influyendo en el cuidado.

Descriptores: Enfermería; Estudiantes de enfermería; Drogas ilícitas. 


\section{INTRODUÇÃO}

O uso de drogas é um grave problema de saúde pública em âmbito mundial. No mundo todo, cerca de 200 milhões de pessoas - Quase 5\% da população entre 15 e 64 anos - usam drogas ilícitas pelo menos uma vez por ano. Aproximadamente metade dos usuários usa drogas regularmente; isto é, pelo menos uma vez por mês ${ }^{(1)}$.

Com ascensão das drogas, Que atualmente assume um de papel de destaque na sociedade, a enfermagem ganha uma nova responsabilidade: aprender ou/e aperfeiçoar, a abordagem a esse público, promovendo e prevenindo esse uso buscando mudar essa realidade.

Destaca-se Que os profissionais de enfermagem são agentes chave no processo da transformação social dos países, participando no desenho e na implantação de programas e projetos de promoção de saúde, prevenção do uso e abuso de álcool e outras drogas e interação social(2).

Mediante a isto buscou-se estudar o assunto e definiu-se como objeto, as concepções dos graduandos de enfermagem sobre a abordagem ao paciente usuário de drogas.

O termo concepção é definido como uma "imagem subjetiva do mundo, concebida por um indivíduo ou grupo, de acordo com determinado ponto de vista"(3).

Baseando-se nesta definição, pode-se inferir Que a concepção se forma a partir de conhecimentos, com contribuições de crenças individuais construídas a partir de culturas distintas.

Uma crença é algo aceito como verdadeiro pelo julgamento da probabilidade, ao invés de sê-lo pela sua realidade ${ }^{(4)}$. Trata-se de um tipo especial de atitude, cujo componente intelectual é baseado mais na fé do Que em um fato. As pessoas apresentam crenças Que podem ser verdadeiras ou Que, com uma evidência confiável, podem ser provadas como verdadeiras.

No caso das drogas, particularmente, as concepções baseadas em crenças que muitas vezes, marginalizam o usuário de drogas a partir de um julgamento de valor pode levar o profissional de saúde a uma abordagem inadeQuada e atitudes não éticas.

Neste aspecto, a indignação moral é o grande obstáculo para a comunicação entre o enfermeiro e o paciente, moral essa fundamentada no sistema de valores da idade média, onde a doença e a dependência eram encaradas, pelos profissionais de enfermagem, como uma punição justificável pelo seu próprio comportamento inadequado ${ }^{(4)}$.

Correlacionando a formação do profissional enfermeiro com a assistência prestada ao paciente envolvido com drogas verifica-se uma defasagem de conhecimentos uma vez Que, a grade curricular não contempla de maneira efetiva, na maioria das instituições de ensino superior, conteúdos suficientes e adequadamente ministrados para dar conta do preparo do enfermeiro para o enfrentamento da problemática oriunda do uso e abuso de substâncias psicoativas ${ }^{(5)}$.

Essa lacuna sobre a temática nas instituições de ensino superior também advém de um despreparo de docentes sobre a Questão das drogas, como revela Gonçalves ${ }^{(6)} \mathrm{em}$ seu estudo sobre a atuação docente na prevenção do uso de drogas, Que revela o despreparo dos docentes para lidar com o assunto drogas.

Percebe-se Que a defasagem de formação sobre a problemática perpassa por décadas e profissionais continuam formando profissionais com conhecimentos superficiais sobre o tema.

Diante desse dado de realidade Questiona-se, a partir do que então seriam formadas as concepções dos estudantes de enfermagem, considerando a fragilidade sobre a temática na graduação e Qual seriam os seus reflexos na abordagem ao usuário de drogas. Estas indagações tornam-se pertinentes, uma vez, o conhecimento se configura como um dos principais pilares da concepção sendo visto com potencial de reconstruir crenças.

$\mathrm{O}$ vácuo curricular sobre o tema em Questão, conjugada a desvalorização de programas governamentais assistenciais para esse público-alvo, agravado pelas dificuldades na assistência por representar para os profissionais, muitas vezes, superação de suas crenças e preconceitos se apresenta como um grande desafio para os futuros profissionais de enfermagem ${ }^{(7)}$.

Esse é um desafio que está posto para os enfermeiros do século XXI, saber lidar com essas situações Que são cotidianas, com segurança, conhecimento e liderança para o encaminhamento das Questões e as tomadas de decisões em diferentes âmbitos ${ }^{(7)}$.

Com as mais diversas finalidades, ao longo de todo percurso histórico das civilizações verifica-se a utilização de drogas, sendo essas para usos mágicos, medicinais, ou uma busca de prazeres e satisfações propiciada pelas substâncias. As finalidades do uso de drogas tomaram novos cursos e atualmente esse consumo é considerado um problema de saúde pública.

O recurso às drogas, inicialmente de cunho religioso ou médico, disseminou-se com o homem nas suas migrações, marginalizandose ou tornando-se culturalmente aceitável ou até mesmo banal. Numa perspectiva histórica podemos dizer Que a droga tornou-se um problema de saúde pública a partir da metade do século XIX ${ }^{(8)}$.

A palavra droga, origina-se do droog (holandês), Que significa folha seca, já Que os medicamentos antigamente eram oriundos de vegetais $^{(9)}$.

As drogas são consideradas todas as substâncias Que, ao serem introduzidas, inaladas, injetadas ou ingeridas provocam alterações no seu funcionamento, modificando uma ou mais funções do organismo $^{(10)}$.

Existem diversos tipos de drogas, entre elas as lícitas as Quais o consumo é legalmente aceito e as ilícitas Que são proibidas. No Brasil a lei 6.368, de 1976 é que regulamenta o uso de drogas ilícitas ${ }^{(11)}$.

Os usuários de drogas são classificados de acordo com a freeüência Que fazem uso dessas substâncias. O CEBRID - Centro Brasileiro de Informações sobre Drogas Psicotrópicas ${ }^{(12)}$, propõe uma estratificação do usuário conforme seu consumo de substâncias Químicas, demonstrado no Quadro 1 .

O uso de drogas não caracteriza a dependência da substância. De acordo com o Ministério da Saúde (OMS), a dependência de drogas é determinada por fatores biológicos, genéticos (hereditariedade), psicológicos, culturais e ambientais ${ }^{(13)}$.

Existem fatores Que predispõe o indivíduo a dependência Química, igualmente assim, no uso de drogas existe também fatores Que deixam o individuo mais suscetível à utilização dessas substâncias. Está mais sujeito ao uso de drogas o indivíduo: sem informações adequadas sobre as drogas e seus efeitos; com uma saúde deficiente; insatisfeito com sua Qualidade de vida; com personalidade vulnerável ou mal integrada; com fácil acesso às drogas ${ }^{(13)}$.

Sob este prisma entende-se Que conhecendo as predisposições 


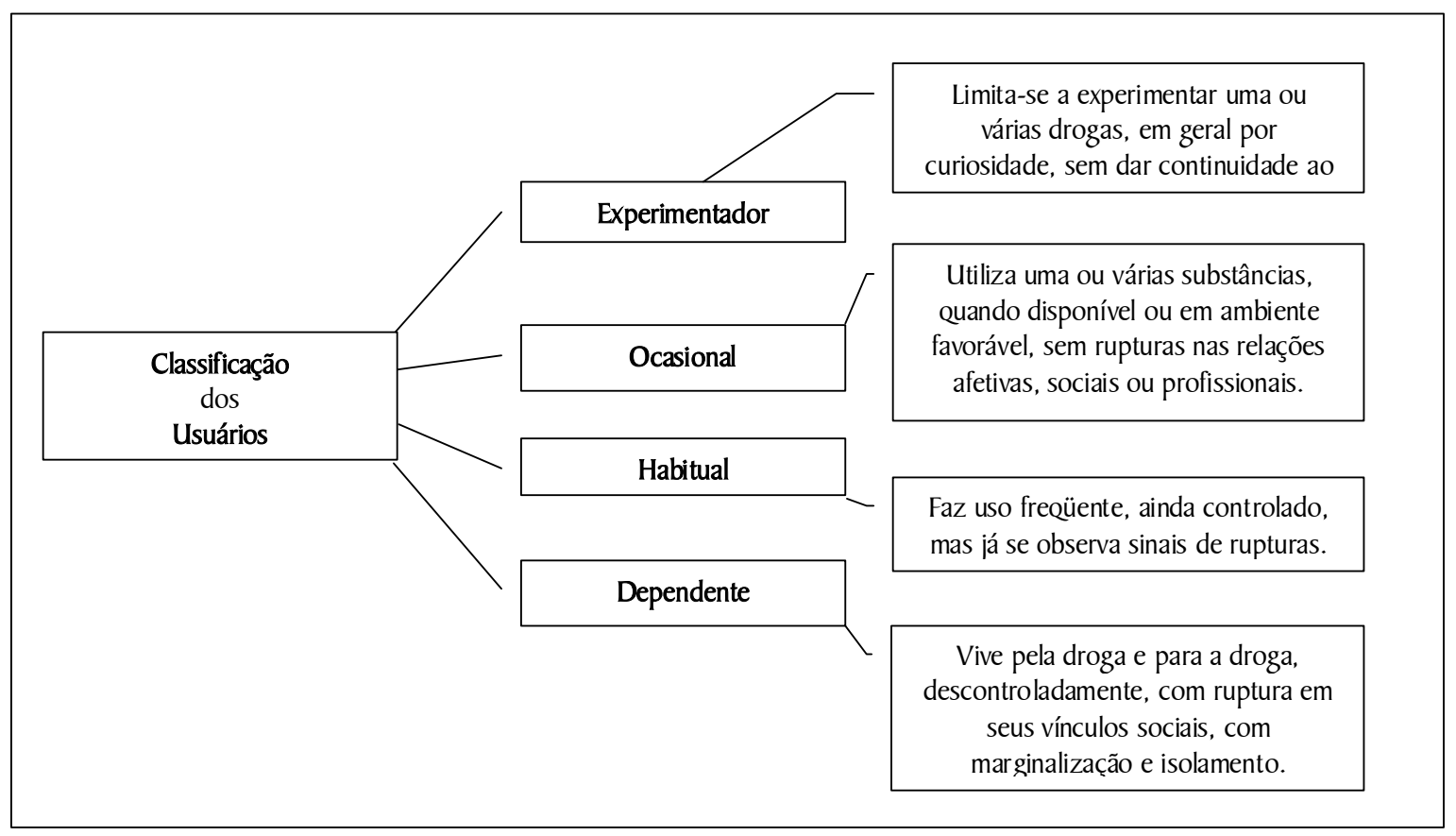

Quadro 1. Classificação dos usuários de drogas.

das pessoas, o enfermeiro ao realizar a anamnese com o paciente ou com seu familiar poderá reconhecer na sua história o ponto de vulnerabilidade, o Que será de grande valia para o trabalho da enfermagem, pois terá um ponto de partida para o tratamento desse paciente podendo atuar de maneira mais eficaz.

Os usuários de drogas, além da sua doença, carregam consigo o pesado fardo do preconceito social. Pensar em preconceito, nos remete logo a idéia de pessoas humildes, ignorantes, Que por falta de informações adequadas sobre assunto, acabam por construir uma imagem desagradável sobre aquele ser humano, Que se encontra doente. Estranho pensar Que pessoas com nível sócio-culturalintelectual elevado, com acesso a informações diversas possam ter uma visão distorcida sobre o paciente Quimicamente dependente.

A forma Que parcela da enfermagem percebe o usuário de drogas não difere muito do senso comum, no Qual estas pessoas são designadas por expressões tais como viciado, bêbado, depravado, sem caráter, pé-de-cana, e Que, muitas vezes é como próprio usuário de álcool se refere a si mesmo ${ }^{(14)}$.

A distorção mencionada advém de crenças e valores altamente moralistas, Que vêem o abuso de substâncias psicoativas como algo absurdamente imoral e inconcebível para uma pessoa descente. Pensamentos estes Que inspiram atitudes Que desmerecem o doente/ dependente.

Na prática assistencial a atenção aos pacientes usuários de drogas deve ser permeada pela compreensão de que pessoas Que fazem uso abusivo de drogas, de maneira a prejudicarem-se ou aos outros, são pessoas Que adoeceram e requerem ser auxiliadas, não sendo portadoras de defeito moral e não devendo ser rejeitadas ou punidas, nem ao menos julgadas principalmente pelos profissionais de saúde.
Estudo realizado com enfermeiros de unidades básicas de saúde e o usuário de drogas, aponta algumas concepções dos profissionais sobre os pacientes. Nesta perspectiva, alguns profissionais concebem o usuário de drogas como pessoas complicadas de se lidar, um pouco delinqüentes, Que vão mentir e enganar o profissional cuidador; as desigualdades sociais são entendidas, pelos enfermeiros, como um impulsionador para o uso de drogas; assim como, a curiosidade, a busca pelo prazer e a solidão como estimulantes; acreditam ser o uso de drogas uma doença, porém na maioria das vezes, vêem esse paciente como doente mental ${ }^{(15)}$. Corroborando este pensamento, outro estudo pontua Que $81 \%$ dos graduandos de enfermagem indicam o enfoQue psiQuiátrico na discussão sobre a temática drogas ${ }^{(16)}$.

Em outro estudo realizado foram observadas concepções diversas entre os entrevistados. Alguns profissionais afirmaram Que o uso de drogas é sempre ruim, "a pior coisa do mundo", mas é referido como prática de escolha de cada um, ressaltando o prejuízo para o indivíduo. Outros o relacionaram à busca de prazeres, busca essa entendida como socialmente valorizada nos dias de hoje, remetendo a problemática do uso de drogas para o campo sócio-cultural ${ }^{(17)}$.

Segundo o mesmo autor, alguns dos profissionais de saúde acreditam que o uso de drogas pode advir de experiências pessoais e afetivas, como carência, desestruturação familiar e o convívio com a violência, outros apostam em aspectos sociais estruturais, como miséria, desemprego e falta de oportunidades ${ }^{(17)}$.

A importância em conhecer como os profissionais de saúde vêem o usuário de drogas, se torna essencial na medida em Que se entende Que maneiras equivocadas de lidar com o assunto, podem levar a prejuízos tanto para o paciente Quanto para o profissional.

Neste aspecto é que se destaca a importância do enfermeiro se 
auto- conhecer, numa tentativa de se lapidar e conseguir ludibriar as debilidades por seus conceitos pessoais, principalmente Quando se trata da temática droga.

A importância do autoconhecimento do enfermeiro, buscando identificar suas próprias crenças, valores e preconceitos em relação ao uso de drogas e aos usuários, adQuirem destacada relevância, pois estes podem estar pouco evidentes, passando despercebidos para o enfermeiro, mas que se manifestam através do comportamento ou abordagens inadequadas no momento do cuidado ou orientação ao usuário de drogas e seus acompanhantes ${ }^{(18)}$.

Neste sentido é pontualmente essencial no exercício da profissão, o enfermeiro ser imparcial no cuidado. A atitude não julgadora passa a ser um reQuisito fundamental na assistência prestada a pessoas usuárias de drogas, e poreue não dizer, a todas as pessoas no cotidiano de nossas vidas ${ }^{(15)}$.

O enfermeiro tem um importante papel de educador em saúde, e para Que sua função como tal seja exercida corretamente é necessário que estes enquanto educadores dispam-se de Qualquer preconceito para Que a assistência prestada a esses pacientes seja eficaz, adequada e irrefutavelmente humana. Pois, reconhecer o outro como sujeito é uma imposição àQueles Que desejam exercer sua profissão na assistência ao usuário de drogas ${ }^{(15)}$.

Para nortear o estudo levantaram-se as seguintes Questões: Qual a concepção dos acadêmicos de enfermagem em relação aos usuários de substâncias psicoativas? Como os estudantes de enfermagem concebem a abordagem ao paciente Que faz uso de substâncias Químicas?

Para responder as Questões norteadoras delinearam-se os seguintes objetivos: Descrever a concepção dos estudantes de enfermagem sobre os usuários de drogas; Analisar os pontos de vista dos estudantes de enfermagem em relação ao usuário de drogas.

\section{MÉTODO}

Estudo descritivo-exploratório desenvolvido em vinte e duas unidades acadêmicas de Quinze Instituições de Ensino Superior de Enfermagem, privadas, do estado do Rio de Janeiro. O critério de inclusão das escolas foi ter alunos matriculados no último período acadêmico por ocasião da pesquisa. As escolas investigadas localizam-se nas regiões do Grande Rio, Serrana, Norte e Sul Fluminense. $\mathrm{O}$ estudo se prende às instituições privadas por já ter sido realizada anteriormente pesquisa com as instituições públicas.

Amostra foi composta de $32 \mathrm{I}$ alunos Que estavam cursando o último período da graduação e Que aceitaram participar voluntariamente da pesQuisa.

O critério de inclusão dos estudantes atendeu às seguintes características: ser aluno regularmente matriculado na instituição de ensino; ter cursado a Escola/Faculdade desde o início da graduação; ser aluno do último período acadêmico; desejar participar voluntariamente da pesquisa.

A coleta dos dados ocorreu entre os meses de junho de 2006 a agosto de 2007. As informações foram obtidas pela pesquisadora e por alunos bolsistas de Iniciação Cientíica e alunos voluntários integrantes do projeto, e contou com apoio integral das escolas investigadas. Apenas uma universidade se recusou a participar da pesquisa. O instrumento utilizado foi uma Escala de Atitudes e
Crenças - NEADA (Nursing Education in Alcool and Drug Education) o Qual faz parte de um programa de treinamento em álcool e drogas para enfermeiros, estudantes e docentes de Enfermagem de Connecticut, EUA, e utilizou três categorias de análise (concordo, indiferente e discordo). O projeto foi aprovado pelo Comitê de Ética do HUPE/UERI com o registro (1 309-CEP/ HUPE). Os estudantes Que aceitaram participar da pesquisa assinaram o Termo de Consentimento Livre e Esclarecido. Foi também elaborado um Termo de Autorização para entrada nos Campos de Pesquisa.

Para obtenção dos dados junto aos estudantes nas diferentes instituições de ensino entrou-se em contato, inicialmente por telefone ou e-mail, com os dirigentes das escolas para agendamento de encontros para apresentação do projeto. Nesta oportunidade procedeu-se a assinatura do termo de aprovação para entrada no campo, assim como foram feitos contatos com os professores referência indicados para acompanhar a execução da coleta dos dados, de acordo com as diretrizes de cada instituição.

Junto a esses professores, foram agendadas datas e locais para a aplicação do Questionário, ocasião em Que, foi apresentado aos alunos o projeto com as informações necessárias solicitando-se a colaboração, bem como a assinatura do Termo de Consentimento Livre e Informado àoueles Que concordaram em participar do estudo.

Para realizar a análise dos dados foram cumpridas as seguintes etapas: realização de um banco de dados no programa estatístico Epi-Info. Foi utilizado ainda o programa Excel para elaboração de tabelas, Quadros e gráficos para apresentação dos resultados. Procedeu-se à discussão dos resultados com suporte da literatura pertinente.

\section{RESULTADOS E DISCUSSÃO}

Os resultados apresentados incorporam Questões Que balizam a maneira como os estudantes vislumbram as ações do enfermeiro em Que pese a sua interlocução com os usuários de substâncias psicoativas. Assim, apresentaremos facetas Que refletem suas concepções, muitas oriundas de sua formação profissional.

Os resultados evidenciam que a maioria dos estudantes acredita ser incômodo para o paciente ser Questionados sobre o uso do álcool e das drogas. $154(48,0 \%)$ concordam, $128(39,8 \%)$ discordam. Tais resultados evocam a necessidade de maior atenção na formação do enfermeiro em relação à temática, considerando ser este profissional muitas vezes o primeiro contato desta clientela nos serviços de saúde. Dos 32 I alunos 39 (12,2\%) colocaram-se indiferente à afirmativa.

Saber o Que perguntar e como perguntar ao paciente se ele faz uso de drogas deve fazer parte do processo de aprendizado do enfermeiro. A reação do cliente as perguntas realizadas pelos profissionais, muitas vezes, está condicionada à forma como é feita a abordagem. Pesquisa realizada sobre Atuação do Enfermeiro na Atenção ao Usuário de Álcool e outras Drogas nos serviços extrahospitalares, evidencia a importância dessa interlocução(2).

$\mathrm{O}$ incomodo referido pelos estudantes muitas vezes se coloca tanto do lado do profissional, Quanto do paciente. O profissional por crenças e estigmas que carrega acerca do usuário de drogas leva-o a um enfrentamento da sua própria ansiedade, insegurança, preconceitos e limitações em lidar com a situação. O paciente por 
sua vez, pode se sentir não muito a vontade de falar em seu problema por toda Questão social Que envolve a utilização de substâncias Químicas, onde o usuário é visto como marginal e como tal vai ser olhado de maneira diferente e até mesmo desprezado em suas necessidades de cuidados. Assumir-se usuário e doente pode implicar em se assumir marginal e excluído da sociedade ${ }^{(2)}$.

Estudo realizado nesta linha de pensamento revela Que o medo do estigma funciona como uma barreira para o dependente Químico chegar a um tratamento ${ }^{(19)}$.

Numa outra perspectiva, os estudantes investigados reafirmam suas concepções sobre o mal estar Que provoca no paciente, Quando ineueridos sobre assuntos de sua vida privada, como a utilização de substâncias psicoativas.

Quando perguntados se "os pacientes ficam irritados Quando os enfermeiros perguntam sobre assuntos pessoais como o uso de álcool e drogas", a maioria dos alunos $156(48,3 \%)$ concorda Que Quando os enfermeiros Questionam o uso de drogas pelos pacientes, isto causa irritabilidade nos mesmos; 100 ( 31 ,3\%) acreditam não proceder essa afirmação e 65 ( 20,4\%) não Quis opinar sobre a Questão.

O enfermeiro pode descobrir Que a empatia é seu instrumento mais valioso ao comunicar-se com seus pacientes ${ }^{(4)}$.

A empatia pode ser um facilitador de aproximação entre o paciente e o profissional levando a redução de dificuldades nessa relação. A irritação titulada pelos estudantes de enfermagem pode ser reduzida ou até mesmo não existir se ocorrer empatia entre paciente e enfermeiro.

Saber como se aproximar do paciente, reconhecendo a sua individualidade e o respeito como um ser cidadão são ferramentas inexoráveis para evitar o constrangimento, além de se constituir em um arcabouço de medidas para minimizar as dificuldades na interlocução com o paciente ${ }^{(20)}$.

Ainda numa perspectiva de negação sobre a abordagem do paciente usuário de drogas, os estudantes acreditam Que o enfermeiro não goza da confiança dos usuários para falar com este sobre o seu uso de substâncias.

Quando indagados "não é provável Que os pacientes contem a verdade sobre seu uso de álcool e drogas Quando entrevistados por um enfermeiro", a maior parcela dos graduandos $185(57,6 \%)$ não acredita na veracidade das respostas dadas pelos pacientes Quando inqueridos pelos enfermeiros sobre o problema das drogas. Discordando dessa pontuação $109(34,0 \%)$ e colocando-se indiferente a Questão 27 (8,4\%).

Um importante passo para uma positiva interlocução com pacientes Que usam drogas é o acolhimento com posterior vinculação aos mesmos. Esse vínculo será fundamental para Que o paciente confie e se sinta a vontade para falar e responder o que lhe for perguntado pelo profissional sem mentiras, sem máscaras. É necessário compreendermos Que os usuários são pessoas Que adoeceram e reQuerem ser auxiliadas, portanto, não devem ser vistas como portadoras de defeito moral, não devendo ser rejeitadas ou punidas $^{(4)}$. Entretanto ainda há uma visão distorcida por parte dos enfermeiros que classificam estas pessoas como complicadas de se lidar, um pouco delineüentes, Que vão mentir e enganar o profissional cuidador $^{(15)}$.

$\mathrm{O}$ vínculo terapêutico favorece a assistência à medida Que o paciente se sente mais a vontade para falar do seu problema ou até mesmo silenciar se for mais conveniente para ele. Desse modo, o vínculo terapêutico também é um balizador das atitudes dos profissionais Que geram em contrapartida a segurança e a confiança do paciente ${ }^{(20)}$. Confiando e se sentindo seguro e protegido o paciente dificilmente terá pudor em falar sobre seu uso de drogas e conseQuentemente não faltará com a verdade para com o profissional de sua confiança.

Por outro lado não podemos perder de vista Que muitas dessas dificuldades de inter-relação estão associadas à falta de conhecimento dos enfermeiros para lidar com um problema com a dimensão do fenômeno das drogas, bem como, o pouco envolvimento dos cursos de formação com o desenvolvimento desta temática, retardando o preparo desse profissional para agir com competência neste campo Que é ao mesmo tempo multicausal, interdisciplinar e multifacetado ${ }^{(7,10,17)}$. Os estudantes acreditam que independente da condição do uso de substâncias o contato Que o enfermeiro tiver com o paciente para falar sobre o seu uso será sempre produtivo, como veremos nos resultados a seguir.

Quando Questionados sobre a improdutividade de manter um diálogo com o paciente usuário de drogas a maioria dos estudantes $197(61,4 \%)$ se posicionou de maneira contrária, enquanto Que 78 (24,3\%) acreditam ser pouco aproveitável e 46 (14,3\%) optaram pela neutralidade no levantamento.

Quando se manifestam de maneira positiva em relação à interlocução com o paciente usuário de drogas, os estudantes compartilham de uma prerrogativa em Que o enfermeiro tem um importante papel de educador em saúde, e para Que sua função como tal seja exercida corretamente é necessário que estes enQuanto educadores dispam-se de Qualquer preconceito para que a assistência prestada a esses pacientes seja eficaz, adequada e irrefutavelmente humana. Pois, reconhecer o outro como sujeito é uma imposição àQueles Que desejam exercer sua profissão na assistência ao usuário de drogas ${ }^{(15)}$. Em menor percentual mais ainda preocupante, segue aQueles Que acreditam na falta de produtividade em um diálogo com usuários de drogas. Isso mostra Que ainda predomina o preconceito da sociedade e dos profissionais em relação ao usuário de álcool e outras drogas e a falta de conscientização destes sobre a importância da aceitação da diferença $a^{(2)}$.

Estes posicionamentos assumidos pelos estudantes nos levam a refletir sobre o Quanto impregnado de crenças particulares estão os futuros profissionais Que irão prestar assistência e como devemos superar estas deficiências conceituais. Eis ai um grande desafio...

\section{CONCLUSÕES}

As drogas se apresentam como um problema importante de saúde, e como tal deve receber adeQuada atenção para a mudança desse Quadro. Para tal processo se faz necessário a capacitação de profissionais de diversas áreas com vistas à possibilidade de mudar essa realidade. Neste cenário, o enfermeiro ascende com um importante papel social de promotor e educador em saúde.

Um papel especial Que só pode ser incorporado mediante o preparo científico apropriado, nos remete à inserção de conteúdos comprovadamente pertinentes sobre a temática nas unidades formadoras de ensino superior.

Os estudantes desta pesquisa deram sinais positivos do seu 
potencial de interlocução com os pacientes usuários de drogas, na medida em Que consideraram a abordagem e o diálogo como fontes e instrumentos Que podem contribuir para assistir estes pacientes livres de preconceitos e discriminações.

Embora os resultados em sua maioria apontem para esta perspectiva, ainda constatamos Que um número expressivo de estudantes manifesta atitudes e crenças Que inviabilizam o estabelecimento de uma relação produtiva com estes pacientes.

Tais dificuldades, no entanto, podem ser administradas mediante o compromisso e empenho dos órgãos formadores, na medida em
Que estes reconheçam Que as drogas hoje se constituem em um problema de saúde pública e Que os enfermeiros são os sustentáculos deste campo do conhecimento, bem como, incorporem em suas grades curriculares conteúdos e práticas Que possibilitem aos profissionais enfrentarem esta situação Que se manifesta em escala global.

Portanto, a mudança da situação das drogas no cenário atual, só será possível, se conjugadas a mudanças de crenças de toda uma população e atitudes acertadas de profissionais comprometidos com a saúde e bem estar social.

\section{REFERÊNCIAS}

1. Escritório das Nações Unidas contra Drogas e Crime - UNODC. [citado em I maio 2008]. Disponível em: http://www.unodc.org

2. Gonçalves SSPM, Tavares CMM. Atuação do enfermeiro na atenção ao usuário de álcool e outras drogas nos serviços extrahospitalares. Esc Anna Nery Rev Enferm 2007; 1 I (4): 586-92.

3. Michaelis - Moderno Dicionário da Língua Portuguesa. [citado em 0 I maio 2008]. Disponível em: http://michaelis.uol.com.br/ moderno/portugues

4. Diniz AS, Ruffino MC. Influência das crenças do enfermeiro na comunicação com o alcoolista. Rev Latino-am Enfermagem 1996; 4(esp): 17-23.

5. Pillon SC. O uso do álcool e a educação formal dos enfermeiros [tese]. São Paulo: Universidade Federal de São Paulo; 2003.

6. Gonçalves SEF. Atuação docente na prevenção do uso de drogas: uma construção no contexto da enfermagem [dissertação]. Rio de Janeiro: Universidade do Estado do Rio de Janeiro; 2006.

7. Carraro TE, Rassool GH, Luis MAV. A formação do enfermeiro e o fenômeno das drogas no sul do Brasil: atitudes e crenças dos estudantes de enfermagem sobre o cuidado. Rev Latinoam Enfermagem 2005; I3(esp): 863-71.

8. Bergeret I, Leblanc I. Toxicomanias. Porto Alegre: Artmed; 1991.

9. Lopes GT. Conhecimentos, atitudes e crenças dos enfermeiros sobre o fenômeno das drogas adeuiridos na graduação: estudo desenvolvido no estado do Rio de laneiro. Rio de Janeiro: Universidade do Estado do Rio de Janeiro; 2006.

10. Barros MA, Pillon SC. Atitudes dos profissionais do programa de saúde da família diante do uso e abuso de drogas.Esc Anna Nery Rev Enferm 2007; 1 I (4): 655-62.

11. Silva MS, Modesto LS, Molinari D. Se liga! O livro das Drogas. Rio de Janeiro: Record; 1997.
12. Centro Brasileiro de Informações sobre Drogas Psicotrópicas CEBRID. Prevenção - algumas definições. [citado em $12 \mathrm{dez}$ 2007]. Disponível em: http://www.unifesp.br/dpsicobio/ pergresp/defini.htm

13. Programa de Prevenção ao Uso de Substâncias Psicoativas Lícitas e Ilícitas na Unicamp. [citado em 12 dez 2007]. Disponível em: http://www.prdu.unicamp.br/vivamais/Projeto.pdf

14. Rosa AJS. Escutando o dependente de álcool: uma abordagem compreensiva [tese]. Ribeirão Preto: Escola de Enfermagem de Ribeirão Preto, Universidade de São Paulo; 2001 .

15. Spricigo IS, Alencastre MB. O enfermeiro da unidade básica de saúde e o usuário de drogas: um estudo em Biguaçú - SC. Rev Latino-am Enfermagem 2004; 12 (4): 427-32.

16. Ramos LH, Pillon SC, Cavalcante MB, Luiz MAV, Padredi F, Laranjeira RR. O ensino sobre dependência Química em Curso de Graduação em Enfermagem no Brasil, 1998. Acta Paul Enferm 2001; 14(3): 35-43.

17. Lima M, Costa IA, Figueiredo WS, Schraiber LB. Invisibilidade do uso de drogas e a assistência de profissionais dos serviços de Aids. Rev Saúde Pública 2007; 4 I (supl 2): 6-13.

18. Luis MAV, Pillon SC. Promoção de saúde e prevenção do uso de drogas:o papel do enfermeiro. Ribeirão Preto: Escola de Eenfermagem de Ribeirão Preto, Universidade de São Paulo; 2002.

19. Fontanella B|B, Turato ER. Barreiras na relação clínico paciente em dependentes de substâncias psicoativas procurando tratamento. Rev Saúde Pública 2002; 36(4): 439-78.

20. Correa SR. O papel humanizante da enfermagem na unidade de psiQuiatria para o tratamento de famacodependência em um hospital geral [monografia]. São Paulo: Programa de Orientação ao Dependente, Universidade Federal de São Paulo; 2002. 